\title{
Cannabinoids and Cannabis Based Medicines in the Treatment of Chronic Pain: A Review H Lowe ${ }^{1,2}$, C Watson ${ }^{1}$, K Smith ${ }^{1}$
}

\begin{abstract}
Cannabinoids isolated from cannabis spp. have been the subject of much research over at least three decades. Extensive research has been conducted on the mode of action of this group of compounds which elicits a variety of therapeutic activity. Research has revealed that phytocannabinoids have similar activity as endocannabinoids and can act as ligands in the endocannabinoid system. The endocannabinoid system is a neuromodulatory system that regulates some important bodily functions. With the existing preclinical and clinical trials and the activity of cannabis derived analgesics, cannabinoids shows great potential in curtailing the concerns of traditional pain modulators. This review article highlights research on cannabinoids as an analgesic in the management of several pain states such as neuropathy, migraine, arthritis, and sickle cell disease.
\end{abstract}

Keywords: Arthritis, cannabinoids, cannabis, chronic pain, migraine, neuropathic pain, sickle cell disease

From: ${ }^{1}$ Bio-Tech R\&D Institute, 44 Lady Musgrave Road Kingston 5, Kingston, Jamaica. ${ }^{2}$ Educational and Scientific Corporation, Florida, USA.

Correspondence: Dr C Watson, Bio-Tech R\&D Institute, Kingston, Jamaica.

Email: charah_twa@yahoo.com 


\section{INTRODUCTION}

The International Association for the Study of Pain (IASP) describes pain as "an unpleasant sensory and emotional experience associated with actual or potential tissue damage, or described in terms of such damage" (1). Chronic pain can be classified as nociceptive or neuropathic, is persistent and occurs as a result of prolonged activation of pain signals in the nervous system lasting longer than three months (2). Common sources of chronic pain include: arthritis pain, lower back pain, headache, cancer pain, neurogenic pain and psychogenic pain. Chronic pain is also a significant reducer of quality of life and may be fatal (3). It poses a significant financial burden, affecting approximately 10 percent of the global population, approximately 600 million people (4). One study estimates the United States' national cost of pain to be between 560 to 635 billion dollars annually (5). There is currently a wide array of drugs ranging from nonsteroidal anti-inflammatory drugs (NSAIDs) to narcotic opioids (e.g. codeine and morphine) that are actively used in pain management. These pain care methods are however faced with several challenges that limit their use including severe adverse effects such as gastrointestinal disturbances associated with NSAIDs and the potential abuse of prescription medication.

Cannabinoids represent viable alternates in the treatment and management of pain (6). Plant cannabinoids are a pharmacological class of over 85 naturally occurring compounds found in several plant species but are most predominant in Cannabis sativa (7). The main subclasses of cannabinoids are; cannabigerols (CBG), cannabichromenes (CBC), cannabidiols (CBD), tetrahydrocannabinols (THC), cannabinol (CBN) and cannabinodiol (CBDL). Several studies using cannabis or cannabis derivatives have shown noteworthy results of Cannabis stimulated pain relief. This article will review research data surrounding cannabis' therapeutic effects in pain associated with neuropathy, migraine, rheumatoid arthritis, osteoarthritis and sickle cell disease. 


\section{The endocannabinoid system}

The endocannabinoid system (ECS) is an ancient neuromodulatory system that comprises endocannabinoids (mainly anandamide and 2-arachidonoylglycerol (2-AG)); the cannabinoid receptors and their deactivators. The ECS is associated with regulation of a variety of physiological processes including sleep, appetite, analgesia and spasticity by binding to CB1 or CB2 receptors thereby regulating the release of various neurotransmitters. The CB1 receptors predominate in the nervous system and glands, and connective tissues, while CB2 receptors are predominantly found peripherally in the immune system and its associated structures. Studies have shown that activation of both $\mathrm{CB} 1$ and $\mathrm{CB} 2$ receptors reduces nociceptive processing in both acute and chronic animal models of pain (8-10).

\section{Cannabis and pain}

\section{Neuropathic Pain}

Neuropathic pain occurs as a result of damaged or dysfunctional nerves in somatosensory system and is generally associated with a disorder such as stroke, diabetes, or spinal cord injury with symptoms including burning, tingling, and numbness or shooting pain. Chronic neuropathic pain affects $1-2 \%$ of the adult population and according to the Neuropathy Association, there are now 15-18 million Americans with diabetes peripheral neuropathy (DPN). There are no statistics on the prevalence of neuropathic pain in Jamaica or the Caribbean, however, diabetes affects approximately $8 \%$ of the local population (11) and a small survey conducted at the University Hospital of the West Indies showed that $82 \%$ of diabetic participants showed clinical signs of neuropathy (12).

Similar to other pain states, neuropathic pain is often refractory to the standard pain medication and is managed with antidepressants and anti-seizure drugs. A randomized controlled 
trial conducted by Ware et al in adults with posttraumatic and postsurgical neuropathy pain revealed that a single inhalation of $25 \mathrm{mg}$ of $9.4 \%$ tetrahydrocannabinol herbal cannabis administered through a pipe three times daily for five days reduced pain intensity and improved sleep (13). A similar study conducted by Wilsey et al in 2013 found that vaporized cannabis at concentrations of $3.53 \%$ and $1.29 \%$ helped with general and peripheral neuropathy in patients who didn't find relief from standard treatment (14).

HIV associated distal sensory predominant polyneuropathy (DSPN) has also been tested using smoked cannabis with THC concentrations ranging from $1-8 \%$ in subjects who had neuropathic pain and were refractory to two previous analgesic classes of drugs. Results showed statistically significant improvements in pain as well as mood and daily functioning with concomitant use of their regular pain medication (15).

Multiple sclerosis (MS) autoimmune disease is the most widespread disabling neurological condition of young adults around the world, with an estimated 2.5 million people with the disease. A study using the THC pill, Dronabinol at $10 \mathrm{mg}$ daily has shown modest yet clinically relevant analgesic effect against central pain in patients suffering from MS. Several studies using the oromucosal cannabis spray, Sativex have also been conducted which show that doses of $27 \mathrm{mg} / \mathrm{mL}$ THC and $25 \mathrm{mg} / \mathrm{mL} \mathrm{CBD}$ are effective in relieving different symptoms associated with neuropathic pain including allodynia, and sleep disturbance. (16-19)

\section{Migraine}

According to the World Health Organization Report 2001, migraine is one of the top twenty (20)causes of disability that is expressed as years of healthy life lost to disability and is more prevalent than diabetes, epilepsy, and asthma combined. According to research conducted by Akerman et al in 2013, endocannabinoids are able to inhibit trigeminovascular nociceptive 
transmission from the brainstem. The research shows that activation of CB1 receptors was able to attenuate neuron pain responses and this effect was inhibited with CB1 receptor antagonist suggesting therapeutic potential of endocannabinoids in migraine. (21)

\section{Arthritis}

Among persons with multiple chronic conditions, arthritis is a common disability, affecting approximately 52.5 million adults in the United States alone (22). Wong et al reported in 2010 that the prevalence of arthritis and rheumatism in South America and the Caribbean ranged from $23.8 \%$ to $56.0 \%$ with a global increase in prevalence with age and the female gender. In the United States the total costs for this disability and other rheumatic conditions were approximately 128 billion dollars in 2003 (23).

Studies show the presence of the endocannabinoid system in the knee joints (24) and the involvement of the endocannabinoid system in the regulation of synovial blood flow in the knee joints (25). In addition, scientists have also found high levels of endocannabinoids as well as the degradative enzyme fatty acid amide hydrolase (FAAH) in the synovia of arthritic patients compared to non-arthritic volunteers suggesting an involvement of the endocannabinoid system in the pathophysiology of the disease (26).

A recent study assessing the efficacy of a sublingually administered cannabinoid drug in the treatment of RA showed significant improvements in pain on movement, pain at rest, quality of sleep and inflammation with no significant adverse effects (27).

\section{Sickle Cell Disease (SCD)}

$10 \%$ of the Jamaican population are carriers of the sickle cell trait making it the most common genetic disorder in the country. Statistics show that approximately $0.33 \%$ of live infant births had the sickle cell disease while $0.67 \%$ had the sickle cell trait or some form of the disease (28). 
Pain is an important symptom of the disease affecting patients as young as six months old. In 2010 and 2011 respectively the University of Minnesota using transgenic mice expressing human sickle haemoglobin $(\mathrm{HbS})$ found that the synthetic THC analogue CP 55, 940 was as effective as morphine sulphate in treating SCD severe pain, and ameliorated severe pain associated with hypoxia / reoxygenation cycle. These studies show that cannabinoids have the potential to be used as treatment for sickle cell crisis, and provide a rationale for further clinical trials to be done $(29,30)$.

\section{Safety of cannabis as an analgesic}

Scientists have highlighted the potential importance of the benefits that can be attained from cannabis treatment of pain (31). Cannabis remedies are considered as a low risk traditional medication, with the most common adverse effect being a euphoric mood and drowsiness associated with the cannabinoid, THC. THC however has been well researched for its analgesic and therapeutic properties; in fact it is seen as a viable replacement for habit forming opioids and has been used in combination with opioids, where the opioid dose was lowered without compromising pain relief, while decreasing the adverse effects of the opioid. THC has shown promise in the management of opioid dependency and in a preclinical study reduced the development of tolerance and withdrawal from opiates. $(32,33)$

After years of use, cannabis has a wide, established safety margin. According to Grinspoon and Bakalar, the use of marijuana as medicine is regarded as safe and the safety as established by animal models is one death in every 40,000 animals. This when compared to the lethality of alcohol which has one death in every 4-10 uses (34). The development of alternative methods for the administration of cannabis based medicine also reduces the risks, real or perceived, associated with cannabis smoking. 


\section{Medicinal cannabis in Jamaica}

The limiting step in medicinal cannabis use is the legality of the drug as well as the establishment or development of standardized forms of the medication. Recent amendments to the Dangerous Drugs Act (DDA) made by the Dangerous Drugs (Amendment) Act 2015 and which came into operation on April 15 $5^{\text {th }}, 2015$ introduced new provisions for possession and smoking, use as a religious sacrament as well as the medical and scientific use of cannabis. Under the new provisions, a Cannabis Licensing Authority (CLA), set up by the DDA will be responsible for creating guidelines for the use of cannabis for medical, therapeutic and scientific purposes. The CLA will have responsibility for issuing licences, permits and the overall regulation of the local cannabis and hemp industry (35).

\section{CONCLUSION}

The activity of cannabinoids in the endocannabinoid system has significantly revealed the multimodality of these compounds in pain modulation. Cannabinoids are seen to complement present pain management therapy such as opioid treatment, which suggests a synergistic relationship with traditional analgesics. With minimal adverse effects and low toxicity, cannabinoid therapy demands more exploration. The future nevertheless, will involve an exchange of stereotypes for scientific facts and stimulating interest to further overcome the challenges experienced with researching cannabinoids. 


\section{REFERENCES}

1. Classification of chronic pain. Descriptions of chronic pain syndromes and definitions of pain terms. Prepared by the International Association for the Study of Pain, Subcommittee on Taxonomy. Pain Suppl 1986; 3: S1-226.

2. Kennedy J, Roll JM, Schraudner T, Murphy S, McPherson S. Prevalence of persistent pain in the U.S. adult population: new data from the 2010 national health interview survey. J Pain 2014; 15: 979-84.

3. Simon LS. Relieving Pain in America: A Blueprint for Transforming Prevention, Care, Education, and Research. J Pain Palliat Care Pharmacother. 2012; 26: 197-8.

4. Jackson TP, Stabile VS, McQueen KAK. The Global Burden of Chronic Pain. ASA Monitor. 2014; 78: 24-7.

5. Gaskin DJ, Richard P. The economic costs of pain in the United States. J Pain 2012; 13: $715-24$.

6. Russo EB. Cannabinoids in the management of difficult to treat pain. Ther Clin Risk Manag 2008; 4: 245-59.

7. ElSohly MA. Marijuana and the Cannabinoids: Springer Science \& Business Media; 2007 2007.

8. Sulak D. Introduction to the endocannabinoid system. P Armentano, Emerging clinical applications for cannabis and cannabinoids: A review of the recent scientific literature. $2011 ; 4: 10-4$.

9. Rani Sagar D, Burston JJ, Woodhams SG, Chapman V. Dynamic changes to the endocannabinoid system in models of chronic pain. Philos Trans R Soc Lond B Biol Sci 2012; 367: 3300-11. 
10. Starowicz K, Malek N, Przewlocka B. Cannabinoid receptors and pain. WIREs Membr Transp Signal 2013; 2: 121-32.

11. Ferguson TS, Francis DK, Tulloch-Reid MK, Younger NOM, McFarlane SR, Wilks RJ. An update on the burden of cardiovascular disease risk factors in Jamaica: findings from the Jamaica Health and Lifestyle Survey 2007-2008. West Indian Med J 2011; 60: 422-8.

12. Richards-George P, Wright-Pascoe R, Choo-Kang E, Reid HL, Mills J, Morrison EY. Some clinical factors contributing to the development of the diabetic foot. West Indian Med J 1999; 48: 223-6.

13. Ware MA, Wang T, Shapiro S, Robinson A, Ducruet T, Huynh T, et al. Smoked cannabis for chronic neuropathic pain: a randomized controlled trial. CMAJ 2010; 182: E694-701.

14. Wilsey B, Marcotte T, Deutsch R, Gouaux B, Sakai S, Donaghe H. Low-dose vaporized cannabis significantly improves neuropathic pain. J Pain 2013; 14: 136-48.

15. Ellis RJ, Toperoff W, Vaida F, van den Brande G, Gonzales J, Gouaux B, et al. Smoked medicinal cannabis for neuropathic pain in HIV: a randomized, crossover clinical trial. Neuropsychopharmacology. 2009; 34: 672-80.

16. Langford RM, Mares J, Novotna A, Vachova M, Novakova I, Notcutt W, et al. A doubleblind, randomized, placebo-controlled, parallel-group study of THC/CBD oromucosal spray in combination with the existing treatment regimen, in the relief of central neuropathic pain in patients with multiple sclerosis. J Neurol. 2013; 260: 984-97.

17. Nurmikko TJ, Serpell MG, Hoggart B, Toomey PJ, Morlion BJ, Haines D. Sativex successfully treats neuropathic pain characterised by allodynia: a randomised, doubleblind, placebo-controlled clinical trial. Pain. 2007; 133: 210-20. 
18. Rog DJ, Nurmikko TJ, Friede T, Young CA. Randomized, controlled trial of cannabisbased medicine in central pain in multiple sclerosis. Neurol 2005; 65: 812-9.

19. Rog DJ, Nurmikko TJ, Young CA. Oromucosal delta9-tetrahydrocannabinol/cannabidiol for neuropathic pain associated with multiple sclerosis: an uncontrolled, open-label, 2year extension trial. Clin Ther 2007; 29: 2068-79.

20. Leonardi M, Steiner TJ, Scher AT, Lipton RB. The global burden of migraine: measuring disability in headache disorders with WHO's Classification of Functioning, Disability and Health (ICF). J Headache Pain 2005; 6: 429-40.

21. Akerman S, Holland PR, Lasalandra MP, Goadsby PJ. Endocannabinoids in the brainstem modulate dural trigeminovascular nociceptive traffic via CB1 and "triptan" receptors: implications in migraine. J Neurosci 2013; 33: 14869-77.

22. Barbour KE, Stevens JA, Helmick CG, Luo YH, Murphy LB, Hootman JM, et al. Prevalence of Doctor-Diagnosed Arthritis and Arthritis-Attributable Activity LimitationUnited States. MMWR Morb Mortal Wkly Rep 2013; 62: 869-73.

23. Wong R, Davis AM, Badley E, Grewal R, Mohammed M. Prevalence of Arthritis and Rheumatic Diseases around the world: A growing burden and implications for Health Care Needs. Technical Report. Models of Care in Arthritis (MOCA), 2010 2010. Report No.

24. Schuelert N, McDougall JJ. Cannabinoid-mediated antinociception is enhanced in rat osteoarthritic knees. Arthritis and rheumatism. 2008; 58: 145-53.

25. McDougall JJ, Yu V, Thomson J. In vivo effects of CB2 receptor-selective cannabinoids on the vasculature of normal and arthritic rat knee joints. Br J Pharmacol 2008; 153: 35866. 
26. Richardson D, Pearson RG, Kurian N, Latif ML, Garle MJ, Barrett DA, et al. Characterisation of the cannabinoid receptor system in synovial tissue and fluid in patients with osteoarthritis and rheumatoid arthritis. Arthritis Res Therapy 2008; 10: R43.

27. Blake DR, Robson P, Ho M, Jubb RW, McCabe CS. Preliminary assessment of the efficacy, tolerability and safety of a cannabis-based medicine (Sativex) in the treatment of pain caused by rheumatoid arthritis. Rheumatol 2006; 45: 50-2.

28. Asnani MR, McCaw-Binns AM, Reid ME. Excess Risk of Maternal Death from Sickle Cell Disease in Jamaica: 1998-2007. PLoS One 2011; 6: e26281.

29. Cain DM, Vang D, Simone DA, Hebbel RP, Gupta K. Mouse models for studying pain in sickle disease: effects of strain, age, and acuteness. Br J Haematol 2012; 156: 535-44.

30. Kohli DR, Li Y, Khasabov SG, Gupta P, Kehl LJ, Ericson ME et al. Pain-related behaviors and neurochemical alterations in mice expressing sickle hemoglobin: modulation by cannabinoids. Blood 2010; 116: 456-65.

31. Joy JE, Watson SJ, Jr., Benson JA, Jr., Others. Marijuana and Medicine: Assessing the Science Base: National Academies Press; 19991999.

32. Cichewicz DL, Martin ZL, Smith FL, Welch SP. Enhancement mu opioid antinociception by oral delta9-tetrahydrocannabinol: dose-response analysis and receptor identification. $\mathrm{J}$ Pharmacol Exp Ther 1999; 289: 859-67.

33. Cichewicz DL, McCarthy EA. Antinociceptive synergy between delta (9)tetrahydrocannabinol and opioids after oral administration. J Pharmacol Exp Ther 2003; 304: 1010-5.

34. Grinspoon L, Bakalar JB. Marihuana as medicine. A plea for reconsideration. JAMA. 1995; 273: 1875-6. 
35. Dangerous Drugs (Amendment) Act 2015 Facts. Ministry of Justice; 2015. p. 1-8. 